\title{
Assessment of Diabetes Health Promotion Behaviors for Clients with Type 2 Diabetes Mellitus at Diabetic Center in Al-Diwaniya City
}

\author{
Haider Fahim Shafeea ${ }^{1}$, Arkan Bahlol Naji ${ }^{2}$ \\ ${ }^{1} \mathrm{MScN}(\mathrm{c})$, Research Scholar, University of Baghdad, College of Nursing, \\ ${ }^{2}$ Professor (PhD), University of Baghdad, College of Nursing, Community Health Nursing Department
}

\begin{abstract}
Background: Diabetes mellitus (DM) is a significant worldwide medical issue that causes high human, social, and financial expenses on nations at all pay levels. The constant hyperglycemia of diabetes is related to long-term damage, brokenness, and disappointment of different organs, particularly of the eyes, kidneys, nerves, heart, and blood vessels.
\end{abstract}

Method: A descriptive correlational design is used in this study which aims to measure health-related experiences and lifestyle behaviors for clients with type 2 diabetes for the period from ( $1^{\text {st }}$ October 2019 to $27^{\text {th }}$ August 2020). The study included a convenience sample of 358 clients with type 2 diabetes mellitus who were recruited from Al-Diwaniya Teaching Hospital at Diabetes and Endocrine Center.

Data were collected using a self-report study instrument that includes the socio-demographic sheet, the health profile, and the Type 2 Diabetes and Health Promotion Scale. The data were analyzed using Statistical Package for Social Sciences (SPSS) version 26 using the frequency, percent, arithmetic mean, standard deviation, Pearson correlation, Independent-sample t-test, and one-way analysis of variance (ANOVA).

The study results displayed that most of participants reported poor Physical Activity level ( $\mathrm{n}=266 ; 74.3 \%$ ), more than two-fifth reported good Risk Reduction level $(\mathrm{n}=148 ; 41.3 \%)$, less than two-fifth reported good Stress Management level $(\mathrm{n}=134 ; 37.4 \%)$, less than two-fifth reported fair Healthy Diet level (n $=135 ; 37.7 \%)$, more than two-fifth reported good overall behavior $(\mathrm{n}=193 ; 53.9 \%)$. Furthermore, there are statistically significant inverse correlations between participants' age and their Physical Activity, Risk Reduction, Stress Management, Enjoying Life, and overall behavior.

Conclusion: The researcher concluded that the younger the clients, the poorer the Physical Activity, Risk Reduction, Stress Management, Enjoying Life, and overall behavior; the older the client, the better the Health Responsibility; the better socioeconomic status, the better the Physical Activity, Risk Reduction, Stress Management, Enjoying Life, and overall behavior.

Keywords: Diabetes, Health Promotion Behaviors, Clients, Type 2 Diabetes Mellitus, Diabetic Center.

\section{Introduction}

Diabetes mellitus (DM) is a significant worldwide medical issue that causes high human, social, and financial expenses on nations at all pay levels. The constant hyperglycemia of diabetes is related to longtermdamage, brokenness, and disappointment of different organs, particularly of the eyes, kidneys, nerves, heart, and blood vessels ${ }^{(1)}$.
Type 2 diabetes mellitus (T2DM) is an interminable illness which frequently creates for quite a long time with no clinical indications. It is the most widely recognized sort of diabetes around the world, the other two regular sorts being type 1 diabetes and gestational diabetes. T2DM represents $85 \%-95 \%$ of analyzed cases. Diabetes just as different ailments of abundance which incorporate heftiness and cardiovascular ailments are a significant wellbeing worry in the $21^{\text {st }}$ century ${ }^{(2)}$. 
Health promotion behavior is the art and study of helping individuals find the cooperative energies between their core interests and ideal wellbeing, improving their inspiration to make progress toward ideal wellbeing, and supporting them in changing their way of life to push toward a condition of ideal wellbeing. Ideal wellbeing is a unique parity of physical, passionate, social, spiritual, and scholarly wellbeing ${ }^{(3)}$. Additionally, health promotion is more relevant today than ever in addressing general health problems. The health situation is situated at unique crossroads as the world is confronting a 'triple weight of maladies' established by the incomplete plan of transferable illnesses, recently rising and reappearing ailments just as the phenomenal ascent of noncommunicable diseases (NCDs) ${ }^{(4)}$. Behaviors applicable to diabetes include self-checking of blood glucose levels, eating healthily, regular physical activity, taking medications as ordered, and the utilize of healthcare services, such as healthcare professional visits, and eye and foot assessments ${ }^{(5)}$.

\section{Method}

A descriptive correlational design is used in this study which aims to measure health-related experiences and lifestyle behaviors for clients with type 2 diabetes for the period from ( $1^{\text {st }}$ October 2019 to $27^{\text {th }}$ August 2020). The study included a convenience sample of 358 clients with type 2 diabetes mellitus who were recruited from Al-Diwaniya Teaching Hospital at Diabetes and Endocrine Center. Data were collected using a self-report study instrument that includes the socio-demographic sheet, the health profile, and the Type 2 Diabetes and Health Promotion Scale. The data were analyzed using Statistical Package for Social Sciences (SPSS) version 26 using the frequency, percent, arithmetic mean, standard deviation, Pearson correlation, Independent-sample t-test, and one-way analysis of variance (ANOVA).

\section{Results}

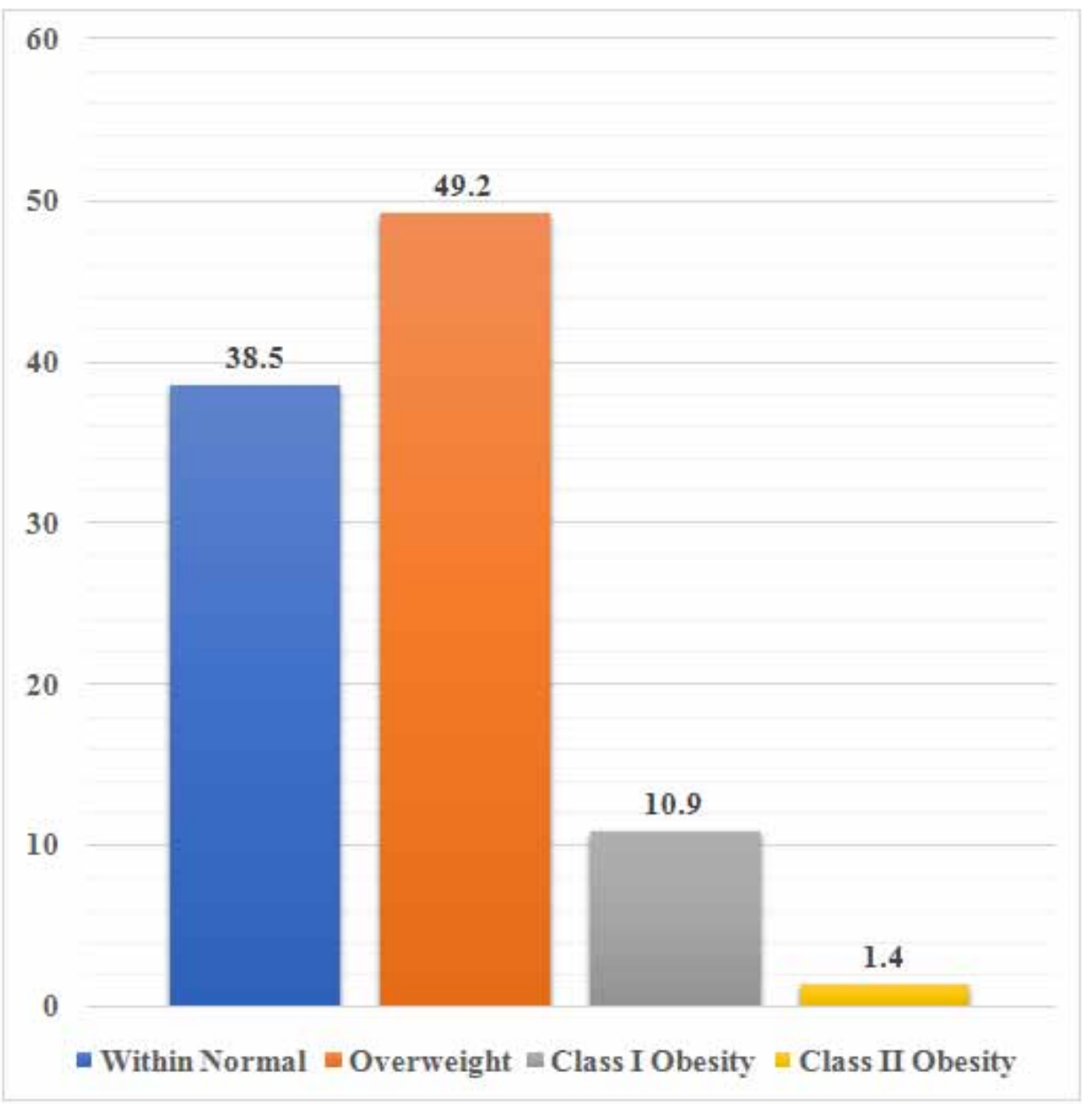

Figure 1. Participants' distribution according to their BMI 
Less than a half are overweight $(\mathrm{n}=176 ; 49.2 \%)$, followed by those who are within normal BMI $(\mathrm{n}=138$; $38.5 \%)$, those who have class I obesity $(\mathrm{n}=39 ; 10.9 \%)$, and those who have class II obesity $(\mathrm{n}=5 ; 1.4 \%)$.

Table 1. Levels of Health-Promoting Lifestyle

\begin{tabular}{|l|c|c|c|c|c|c|}
\hline \multirow{2}{*}{} & \multicolumn{2}{|c|}{ Poor } & \multicolumn{2}{c|}{ Fair } & \multicolumn{2}{c|}{ Good } \\
\cline { 2 - 7 } & Frequency & Percent & Frequency & Percent & Frequency & Percent \\
\hline Physical Activity & 266 & 74.3 & 48 & 13.4 & 44 & 12.3 \\
\hline Risk Reduction & 73 & 20.4 & 137 & 38.3 & 148 & 41.3 \\
\hline Stress Management & 98 & 27.4 & 126 & 35.2 & 134 & 37.4 \\
\hline Healthy Diet & 134 & 37.4 & 135 & 37.7 & 89 & 24.9 \\
\hline Overall & 105 & 29.3 & 60 & 16.8 & 193 & 53.9 \\
\hline
\end{tabular}

Most of participants reported poor Physical Activity level $(n=266 ; 74.3 \%)$, followed by those who reported fair level $(\mathrm{n}=48 ; 13.4 \%)$, and those who reported good level $(n=44 ; 12.3 \%)$.

More than two-fifth reported good Risk Reduction level $(n=148 ; 41.3 \%)$, followed by those who reported fair level $(n=137 ; 38.3 \%)$, and those who reported poor level $(\mathrm{n}=73 ; 20.4 \%)$.

Less than two-fifth reported good Stress Management level $(\mathrm{n}=134 ; 37.4 \%)$, followed by those who reported fair level $(\mathrm{n}=126 ; 35.2 \%)$, and those who reported poor level $(\mathrm{n}=98 ; 27.4 \%)$.

Less than two-fifth reported fair Healthy Diet level ( $\mathrm{n}=135 ; 37.7 \%)$, followed by those who reported poor level $(\mathrm{n}=134 ; 37.4 \%)$, and those who reported good level $(\mathrm{n}=89 ; 24.9 \%)$.

Ultimately, more than two-fifth reported good overall behaviour $(\mathrm{n}=193 ; 53.9 \%)$, followed by those who reported poor level $(\mathrm{n}=105 ; 29.3 \%)$, and those who reported fair level $(n=60 ; 16.8 \%)$.

Table 2. Correlations among Study Variables

\begin{tabular}{|l|c|c|c|c|c|c|c|c|c|c|}
\hline & $\mathbf{1 .}$ & $\mathbf{2 .}$ & $\mathbf{3 .}$ & $\mathbf{4 .}$ & $\mathbf{5 .}$ & $\mathbf{6 .}$ & $\mathbf{7 .}$ & $\mathbf{8 .}$ & $\mathbf{9 .}$ & $\mathbf{1 0 .}$ \\
\hline 1. Age & - & & & & & & & & & \\
\hline 2. SE status & $-.184^{* *}$ & - & & & & & & & & \\
\hline 3. BMI & $.264^{* *}$ & $-.140^{* *}$ & - & & & & & & & \\
\hline 4. Physical Activity & $-.429^{* *}$ & $.461^{* *}$ & $-.199^{* *}$ & - & & & & & & \\
\hline 5. Risk Reduction & $-.321^{* *}$ & $.579^{* *}$ & -.085 & $.584^{* *}$ & - & & & & & \\
\hline 6. Stress Management & $-.262^{* *}$ & $.499^{* *}$ & -.037 & $.558^{* *}$ & $.815^{* *}$ & - & & & & \\
\hline 7. Enjoy Life & $-.269^{* *}$ & $.451^{* *}$ & -.021 & $.474^{* *}$ & $.791^{* *}$ & $.833^{* *}$ & - & & & \\
\hline 8. Health Responsibility & $.255^{* *}$ & -.008 & $.371^{* *}$ & .012 & $.211^{* *}$ & $.273^{* *}$ & $.220^{* *}$ & - & & \\
\hline 9. Healthy Diet & -.035 & $.482^{* *}$ & $.126^{*}$ & $.418^{* *}$ & $.638^{* *}$ & $.579^{* *}$ & $.589^{* *}$ & $.440^{* *}$ & - & \\
\hline 10. Overall & $-.310^{* *}$ & $.570^{* *}$ & -.038 & $.767^{* *}$ & $.908^{* *}$ & $.892^{* *}$ & $.837^{* *}$ & $.354^{* *}$ & $.741^{* *}$ & - \\
\hline
\end{tabular}

${ }^{*}$ Correlation is significant at the 0.05 level (2-tailed)., ${ }^{* *}$ Correlation is significant at the 0.01 level (2-tailed).

There are statistically significant inverse correlations between participants' age and their Physical Activity, Risk Reduction, Stress Management, Enjoying Life, and overall behavior $(\mathrm{r}=-.429$, at $\mathrm{p}<0.01 ; \mathrm{r}=-.321$, at $\mathrm{p}$ $<0.01 ; \mathrm{r}=-.262$, at $\mathrm{p}<0.01 ; \mathrm{r}=-.269$, at $\mathrm{p}<0.01 ; \mathrm{r}=$
-.310 , at $\mathrm{p}<0.01$ ) respectively. On the other hand, there is a statistically significant positive correlation between participants' age and their Health Responsibility ( $r=$ .255 , at $\mathrm{p}<0.01)$. 
There are statistically significant positive correlations between participants' socioeconomic status and their Physical Activity, Risk Reduction, Stress Management, Enjoying Life, and overall behavior $(\mathrm{r}=$ -.461 , at $\mathrm{p}<0.01 ; \mathrm{r}=-.579$, at $\mathrm{p}<0.01 ; \mathrm{r}=-.499$, at $\mathrm{p}$ $<0.01 ; \mathrm{r}=-.451$, at $\mathrm{p}<0.01 ; \mathrm{r}=-.482$, at $\mathrm{p}<0.01 ; \mathrm{r}=$ -.750 , at $\mathrm{p}<0.01$ ) respectively.
There is statistically significant inverse correlation between participants' BMI and their Physical Activity $(\mathrm{r}=-.199$, at $\mathrm{p}<0.01)$. On the other hand, there are statistically significant positive correlations between participants' BMI and their Health Responsibility and Healthy Diet $(r=.371$, at $\mathrm{p}<0.01 ; \mathrm{r}=.126$, at $\mathrm{p}<0.05)$ respectively.

Table 3. Difference in Health-Promoting Lifestyle Between BMI Groups

\begin{tabular}{|c|c|c|c|c|c|c|}
\hline \multicolumn{7}{|c|}{ ANOVA } \\
\hline & & Sum of Squares & df & Mean Square & $\mathbf{F}$ & Sig. \\
\hline \multirow{3}{*}{ Physical Activity } & Between Groups & 1797.537 & 3 & 599.179 & 9.188 & .000 \\
\hline & Within Groups & 23086.656 & 354 & 65.217 & & \\
\hline & Total & 24884.193 & 357 & & & \\
\hline \multirow{3}{*}{ Risk Reduction } & Between Groups & 184.698 & 3 & 61.566 & 1.188 & .314 \\
\hline & Within Groups & 18348.701 & 354 & 51.832 & & \\
\hline & Total & 18533.399 & 357 & & & \\
\hline \multirow{3}{*}{ Stress Management } & Between Groups & 222.532 & 3 & 74.177 & 2.533 & .057 \\
\hline & Within Groups & 10366.988 & 354 & 29.285 & & \\
\hline & Total & 10589.520 & 357 & & & \\
\hline \multirow{3}{*}{ Enjoy Life } & Between Groups & 55.551 & 3 & 18.517 & 1.512 & .211 \\
\hline & Within Groups & 4336.348 & 354 & 12.250 & & \\
\hline & Total & 4391.899 & 357 & & & \\
\hline \multirow{3}{*}{$\begin{array}{l}\text { Health } \\
\text { Responsibility }\end{array}$} & Between Groups & 463.989 & 3 & 154.663 & 16.169 & .000 \\
\hline & Within Groups & 3386.212 & 354 & 9.566 & & \\
\hline & Total & 3850.201 & 357 & & & \\
\hline \multirow{3}{*}{ Healthy Diet } & Between Groups & 65.531 & 3 & 21.844 & 2.076 & .103 \\
\hline & Within Groups & 3725.332 & 354 & 10.524 & & \\
\hline & Total & 3790.863 & 357 & & & \\
\hline \multirow{3}{*}{ Overall } & Between Groups & 4005.947 & 3 & 1335.316 & 2.283 & .079 \\
\hline & Within Groups & 207054.816 & 354 & 584.901 & & \\
\hline & Total & 211060.763 & 357 & & & \\
\hline
\end{tabular}

There are statistically significant differences in Physical Activity Health Responsibility among the BMI groups (P-value $=.000, .000)$ respectively.

Table 4. Difference in Health-Promoting Lifestyle between SE Class Groups

\begin{tabular}{|l|l|c|c|c|c|c|}
\hline \multicolumn{9}{|c|}{ ANOVA } \\
\hline \multirow{3}{*}{ Physical Activity } & Sum of Squares & df & Mean Square & F & Sig. \\
\hline & Between Groups & 4577.878 & 4 & 1144.470 & 19.895 & .000 \\
\cline { 2 - 8 } & Within Groups & 20306.315 & 353 & 57.525 & & \\
\cline { 2 - 8 } & Total & 24884.193 & 357 & & & \\
\hline
\end{tabular}




\begin{tabular}{|c|c|c|c|c|c|c|}
\hline \multicolumn{7}{|c|}{ ANOVA } \\
\hline & & Sum of Squares & df & Mean Square & $\mathbf{F}$ & Sig. \\
\hline \multirow{3}{*}{ Risk Reduction } & Between Groups & 5580.732 & 4 & 1395.183 & 38.023 & .000 \\
\hline & Within Groups & 12952.667 & 353 & 36.693 & & \\
\hline & Total & 18533.399 & 357 & & & \\
\hline \multirow{3}{*}{ Stress Management } & Between Groups & 2411.473 & 4 & 602.868 & 26.022 & .000 \\
\hline & Within Groups & 8178.046 & 353 & 23.167 & & \\
\hline & Total & 10589.520 & 357 & & & \\
\hline \multirow{3}{*}{ Enjoy Life } & Between Groups & 781.805 & 4 & 195.451 & 19.111 & .000 \\
\hline & Within Groups & 3610.094 & 353 & 10.227 & & \\
\hline & Total & 4391.899 & 357 & & & \\
\hline \multirow{3}{*}{$\begin{array}{l}\text { Health } \\
\text { Responsibility }\end{array}$} & Between Groups & 20.596 & 4 & 5.149 & .475 & .754 \\
\hline & Within Groups & 3829.605 & 353 & 10.849 & & \\
\hline & Total & 3850.201 & 357 & & & \\
\hline \multirow{3}{*}{ Healthy Diet } & Between Groups & 908.546 & 4 & 227.136 & 27.818 & .000 \\
\hline & Within Groups & 2882.317 & 353 & 8.165 & & \\
\hline & Total & 3790.863 & 357 & & & \\
\hline \multirow{3}{*}{ Overall } & Between Groups & 59981.490 & 4 & 14995.372 & 35.037 & .000 \\
\hline & Within Groups & 151079.273 & 353 & 427.987 & & \\
\hline & Total & 211060.763 & 357 & & & \\
\hline
\end{tabular}

There are statistically significant differences in Physical Activity, Risk Reduction, Stress Management, Enjoying Life, Health Diet, and overall behavior among the socioeconomic class groups (P-value $=.000, .000$, $.000, .000, .000, .000)$ respectively.

\section{Discussion}

Physical activity is one of the most important modifiable determinants of disease. The study findings that most of participants reported poor Physical Activity level, followed by those who reported fair level, and those who reported good level. This finding is consistent with $^{(6)}$ who concluded that most of study participants have low level of physical activity. More than two-fifth reported good Risk Reduction level $(n=148 ; 41.3 \%)$, followed by those who reported fair level $(\mathrm{n}=137$; $38.3 \%)$, and those who reported poor level $(\mathrm{n}=73$; $20.4 \%$ ). This finding could be explained as that clients may sensitize the seriousness of DM. This finding is consistent with ${ }^{(7)}$ who stated that the scores of Risk Reduction for more than a half of the study participants were high. Less than two-fifth reported good Stress Management level, followed by those who reported fair level, and those who reported poor level. This finding is lower than that reported by ${ }^{(8)}$ who reported that most of study participants have good response to stress management. Less than two-fifth reported fair Healthy Diet level ( $\mathrm{n}=135 ; 37.7 \%)$, followed by those who reported poor level $(\mathrm{n}=134 ; 37.4 \%)$, and those who reported good level $(n=89 ; 24.9 \%)$. This finding reflects participants' poor health literacy; particularly about the healthy diet and its vital role in management of DM. This finding is lower than that reported by ${ }^{(7)}$ who reported that most of the study displayed good commitment to healthy diet. Ultimately, more than two-fifth reported good overall behaviour, followed by those who reported poor level, and those who reported fair level. This finding goes in line with ${ }^{(7)}$ who reported that more than a half of the study participants have good response to the domains of Physical Activity, Risk Reduction, Healthy Diet, and Stress Management. There were statistically significant inverse correlations between participants' age and their Physical Activity, Risk Reduction, Stress Management, Enjoying Life, and overall behavior. On the other hand, there is a statistically significant positive correlation between participants' age and their Health 
Responsibility. This finding could be explained as that the younger the client, the more the physical activity level they enjoy which enable them to adopt healthier health-promoting behaviors. Further cross-tabulation demonstrates that younger clients have higher educational levels. As such, clients who have higher educational levels could have better health awareness which provoke them to adopt health promotive behaviors. This finding is congruent with ${ }^{(9,10)}$ who concluded that there was a statistically significant correlation between participants' age and the Physical Activity, Risk Reduction, Stress Management, Enjoy Life, and their overall behavior. There were statistically significant positive correlations between participants' socioeconomic status and their Physical Activity, Risk Reduction, Stress Management, Enjoying Life, and overall behavior. This finding could be explained as that the better the socioeconomic status the family has, the greater the opportunity to engage in physically active lifestyle, healthier diet, and seeking mental health counseling. This finding is consistent with $^{(11,12)}$ who stated that there was a significant effect of socioeconomic status and each of Physical Activity, Risk Reduction, Stress Management, Enjoying Life, and overall behavior. There was a statistically significant inverse correlation between participants' BMI and their Physical Activity. This finding could be explained as that the higher the body mass index, the poorer the ability of the individual to practice physical activity. On the other hand, there were statistically significant positive correlations between participants' BMI and their Health Responsibility and Healthy Diet. This finding be explained as that as the individuals has high BMI, they may sensitize a greater health threat which render them be more responsible in terms of their health and try to adopt a healthy diet. There were statistically significant differences in Physical Activity Health Responsibility among the BMI groups. Further post hoc analysis demonstrates that clients whose BMI is within normal have better Physical Activity levels. This finding could be explained as that the physical movement for individuals whose BMI is within normal would be easier than those whose BMI is higher. There was statistically significant difference in Physical Activity, and overall behavior among the socioeconomic class groups. Further post hoc analysis displays that the better the socioeconomic class, the better the Physical Activity level. This finding could be explained as that individuals with better socioeconomic status have better capabilities to have physical activity devices and/ or seeking sport clubs or gyms than those with poorer socioeconomic status. There was statistically significant difference in Risk Reduction among the socioeconomic class groups. Further post hoc analysis displays that the better the socioeconomic class, the better the Risk Reduction abilities. This finding could be explained as that individuals with better socioeconomic status have higher educational levels which in turn enable them to have better capabilities of Risk Reduction. There was statistically significant difference in Stress Management among the socioeconomic class groups. Further post hoc analysis exhibits that the better the socioeconomic class, the better the Stress Management abilities. This finding could be explained as that individuals with better socioeconomic status could not be occupied with earn living. In other words, poor socioeconomic status could occupy individuals with earn living and hinder them from seeking mental health counseling. There was statistically significant difference in Enjoying Life among the socioeconomic class groups. Further post hoc analysis exhibits that the Enjoying Life scores were higher among individuals with better socioeconomic class. This finding could be explained as that individuals with better socioeconomic status could have better opportunities for recreation and leisure than those with poorer socioeconomic status. There was statistically significant difference in Health Diet among the socioeconomic class groups. Further post hoc analysis displays that the better the socioeconomic class, the better the Health Responsibility abilities. There was statistically significant difference in Healthy Diet among the socioeconomic class groups. Further post hoc analysis displays that the better the socioeconomic class, the better the Healthy Diet level. This finding could be explained as that individuals with better socioeconomic status have better capabilities to buy healthy foods than those with poorer socioeconomic status. There was statistically significant difference in overall Health Promotion Behaviors among the socioeconomic class groups. Further post hoc analysis displays that the better the socioeconomic class, the better the Health Promotion Behaviors. This finding could be explained as that individuals with better socioeconomic status have better Physical Activity, Risk Reduction, Stress Management, Enjoying Life than those with poorer socioeconomic status.

\section{Conclusions}

1. Most of study subjects are physically inactive and have poor stress management abilities. 
2. Most of study subjects have been used to unhealthy diet.

3. The younger the clients, the poorer the Physical Activity, Risk Reduction, Stress Management, Enjoying Life, and overall behavior.

\section{Recommendations:}

1. There is a need to establish health education activities that aim to improve the physical activity level for individuals with DM type 2.

2. There is a need to establish health education activities to younger clients with DM type 2 that serve to raise their health awareness about the Health Responsibility.

3. There is a need to initiate health promotion activities that target older clients with DM type 2 that seek to improve their Physical Activity, Risk Reduction, Stress Management, and Enjoying Life.

Conflict of Interest: The researchers confirm that there is no any conflict of interest.

Source of Funding: This study is self-funded.

Ethical Clearance: The researchers obtained the ethical approval from the University of Baghdad, College of Nursing.

\section{References}

1. Díaz S, Dilla T, \& Reviriego J. Observational studies with type 2 diabetes mellitus treatments in Spain: A systematic literature review. Endocrinological, diabetes nutrition, 2019 66(4), 254-270.

2. Rosiek A, Kornatowski T, FrąckowiakMaciejewska N, Rosiek-Kryszewska A, Wyżgowski P, \& Leksowski K. Health behaviors of patients diagnosed with type 2 diabetes mellitus and their influence on the patients' satisfaction with life. Therapeutics and clinical risk management, $201612,1783$.

3. O'Donnell MP. Definition of Health Promotion 2.0: Embracing Passion, Enhancing Motivation, Recognizing Dynamic Balance, and Creating Opportunities. American Journal of Health Promotion, 201224 (1), iv-iv.
4. Kumar S, \& Preetha GS. Health promotion: an effective tool for global health. Indian journal of community medicine: official publication of Indian Association of Preventive \& Social Medicine, 2012 37(1), 5 .

5. McSharry J, Byrne M, Casey B, Dinneen SF, Fredrix M, Hynes L, Morrissey E, et.al.Behavior change in diabetes: behavioral science advancements to support the use of theory. Diabetic Medicine, 2020 37(3), 455-463.

6. Mukanoheli V, Uwamahoro MC, Mbarushimana V, $\&$ Meharry P. Functional Health Literacy and SelfCare Behaviors Among Type 2 Diabetic Patients at a University Teaching Hospital in Kigali. Rwanda Journal of Medicine and Health Sciences, 2020 3(1), 49-59.

7. Mohammed-Ali BR, \& Hamza R. Assessment of self-care activities for patients with diabetes mellitus type II. Int. J. Sci. Res. Publ, 2016 6, 425434.

8. Babazadeh T, Dianatinasab M, Daemi A, Nikbakht HA, Moradi F, \& Ghaffari-Fam S. Association of self-care behaviors and quality of life among patients with type 2 diabetes mellitus: Chaldoran County, Iran. Diabetes \& Metabolism Journal, 2017 41(6), 449-456.

9. Freitas SS, da Silva GRF, Neta DSR, \& Silvada ARV. Analysis of the self-care of diabetics according to by the Summary of Diabetes SelfCare Activities Questionnaire (SDSCA). Acta Scientiarum. Health Sciences, 2014 36(1), 73-81.

10. Mohebi S, Parham M, Mozafarion Pour E, \& Kamran A. Self-care Assessment in Patients with Diabetes in Qom city in 2013. Archives of Hygiene Sciences, 2014 3(4), 167-176.

11. Berhe KK, Kahsay AB, \& Gebru HB. Adherence to diabetes Self-management practices among type II diabetic patients in Ethiopia:A cross sectional study. Green J Med Sci, 2013 3(6), 211-221.

12. Viji PT, \& Singh MA. study to assess the practice of diabetic patient towards self-care activities for longevity of life. Scholars Journal of Applied Medical Sciences, 2014 2, 57-60. 